www.jmscr.igmpublication.org

Index Copernicus Value: 79.54

ISSN (e)-2347-176x ISSN (p) 2455-0450

crossrefDOI: https://dx.doi.org/10.18535/jmscr/v7i2.141

Journal Of Medical Science And Clinical Research

\title{
Sonographic Parameters in the Evaluation of Fetal Growth Restriction
}

\author{
Authors \\ Dr Muthiah P. ${ }^{1}$, Dr Pradeep Vel $\mathbf{M}^{2}$, Dr Adaikappan M. $^{3}$ \\ ${ }^{1}$ Associate Professor in Radiology, Raja Muthiah Medical College, Annamalainagar, Chidambaram \\ ${ }^{2}$ Resident, Raja Muthiah Medical College, Annamalainagar, Chidambaram \\ ${ }^{3}$ Professor and Head of the Department, Raja Muthiah medical college, Annamalainagar, Chidambaram \\ Email:pradeepmvel@gmail.com
}

\begin{abstract}
Introduction: The World Health Oraganisation (WHO) has defined Low birth Weight (LBW) as babies weighing less than 2500 grams at birth irrespective of their gestational age. In developed countries, the incidence of $L B W$ is less than 10\% whereas in developing countries, it is in the range of $15-30 \%$ of the total births ${ }^{[1]}$. In India about $30 \%$ of babies born are of $L B W$ due to Prematurity whereas the rest represent growth retarded babies ${ }^{[2]}$. Early detection of Intra Uterine Growth Restriction [IUGR] is of paramount importance for the clinician and hence apart from clinical evaluation, Ultrasound has gained a significant role in the evaluation of IUGR.

Aim: The aim of the study is to confirm the diagnosis of IUGR sonographically in clinically suspected patients using multiple parameters, to correlate the sonographic assessment of the fetus with the postnatal clinical assessment of the neonate and to analyze the predictability of each parameter used for diagnosis with the outcome of the results.

Materials and Methods: A total of 100 antenatal patients referred for ultrasound with clinical suspicion of IUGR are evaluated with various sonographic parameters and the parameters are assessed with the clinical outcome.

Results: After evaluation of 100 suspected cases of intrauterine growth retardation it is concluded that Intrauterine growth retardation is a multi-factorial disease with varying degree of severity. It is unlikely that a single Sonographic parameter will allow an accurate diagnosis in all cases. The type and degree of IUGR depends on the intensity and duration of the underlying disease. Thus, an ultrasound assessment performed long before delivery may be of limited value. Most of the sonographic parameters are gestational age dependent. Gestational age independent indices such as the AFV, the r BPD, the $r A C$ and FLAC ratio are helpful in this situation.

Conclusion: The diagnosis of IUGR depends on combination of multiple parameters rather than a single parameter and this has resulted in a high positive predictive rate of $95.35 \%$.

Keywords: Intra Uterine Growth Restriction, Sonographic Parameters.
\end{abstract}

\section{Introduction}

Intrauterine growth restriction is one of the most commonly recognised abnormalities of the fetal condition and is known to be a confounding factor in $26 \%$ or more still births ${ }^{[3]}$. This carries upto seven fold increased risk of perinatal mortality and significant increase in the risk of perinatal morbidity $^{[4]}$.

Detection of intrauterine growth restriction is such an important problem that reliable methods of 
detection during pregnancy are desirable. Since clinical methods are not much reliable for the diagnosis of this condition ultrasonographic evaluation gained popularity. The clinician is faced with two problems- early recognition of growth restriction and assessment of the fetal well being which dictates the management.

Ultrasonography with its inherent advantages of being a simple, cheap, readily available and a safe, non-invasive investigation has attained prime importance in both the diagnostic and the management protocol of IUGR. Various parameters are used in identifying and evaluating IUGR. In this present study all these parameters used for evaluating IUGR are analyzed for their sensitivity and specificity.

\section{Materials and Methods}

The patients for this study were selected from the antenatal outpatient department of a large general hospital in Pune, India. The study was spread over a period of 24 months from April 1999 to April 2001. The study population consisted of a total of 100 patients who were referred from the antenatal OPD with the clinical diagnosis of IUGR based upon a discrepancy of at least 4 weeks size between gestational age and fundal height. It also included patients from high-risk groups associated with IUGR as well as patients with unsure menstrual dates. The patients with decreased fundal height due to transverse lie were excluded from this study. All the neonates included in the study were weighed at birth. The gestational age was determined by the Ballard's modification of the Dubowitz criteria on the second day after birth
[5]. Based on the gestational age, the infant was classified as IUGR if its weight fell below the 10th percentile for gestational age on the growth chart. The infant was classified as normal if its weight was above the 10th percentile for gestation age.

\section{Statistical Analysis}

Statistical analysis was done by applying descriptive statistics. The categorical data is expressed in the manner of percentage and presented by tables.

\section{Observations and Results}

A total of 117 patients were referred with a clinical diagnosis of IUGR. These included patients with various factors for IUGR and patients with unsure or unreliable menstrual dates. Out of these 117 patients, twelve patients (10.2\%) were excluded from the study because of obvious mistaken dates $(\mathrm{N}=7)$ or transverse lie $(\mathrm{N}=5)$. None of the patients who were excluded on these criteria delivered an infant with IUGR. Five patients $(4.2 \%)$ were lost to follow-up and are excluded from the study. The remaining 100 patients form the basis of this report. All these 100 patients had a minimum of 4 weeks discrepancy between clinical estimation based on uterine fundal height above the pubic symphysis and menstrual dates. In 72 patients (72\%), the LMP (last menstrual period) was known and in 28 patients (28\%), the LMP was uinknown. Of the total of 100 patients, 56 were delivered of an infant of IUGR.

Table 1: Post-Natal Outcome

\begin{tabular}{|l|c|c|c|}
\hline \multirow{2}{*}{ Group } & Birth weight percentile & \multicolumn{2}{|c|}{ Number of patients } \\
\cline { 2 - 4 } & C Ranking & $\mathbf{N}$ & $\mathbf{\%}$ \\
\hline \multirow{2}{*}{ Group I (AGA) } & a) 10th - 25th & 18 & 18 \\
\cline { 2 - 4 } & b) > 25th & 26 & 26 \\
\hline Group II (SGA) & $<10$ th & 56 & 56 \\
\hline \multicolumn{2}{|c|}{ Total } & 100 & 100 \\
\hline
\end{tabular}

On the basis of the weight for gestation age charts, the neonates were divided into two groups as given in table 1. Thus, on the basis of diagnosis by clinical means alone, the false positive rate was
$44 \%$ (44 out of 100 patients). There were a total of 4 perinatal deaths (4\%) - all occurred amongst the infants from Groups II. 
Table 2: Age Distribution

\begin{tabular}{|l|c|c|c|}
\hline \multirow{2}{*}{ Age (in years) } & \multirow{2}{*}{$\begin{array}{c}\text { Total no. of } \\
\text { Patients }\end{array}$} & \multicolumn{2}{|c|}{$\begin{array}{c}\text { Patients with Group II } \\
\text { Infants (IUGR) }\end{array}$} \\
\cline { 3 - 4 } & & $\mathbf{N}$ & $\mathbf{\%}$ \\
\hline $18-20$ & 24 & 16 & 16 \\
\hline $21-23$ & 30 & 17 & 17 \\
\hline $24-26$ & 19 & 9 & 9 \\
\hline $27-29$ & 13 & 7 & 7 \\
\hline $30-32$ & 6 & 2 & 2 \\
\hline $33-35$ & 5 & 3 & 3 \\
\hline $36-38$ & 3 & 2 & 2 \\
\hline Total & 100 & 56 & 56 \\
\hline
\end{tabular}

The range was from 18-38 years with a mean of

The parity of the referred patients along with the $23.2+4.5$ years. number who were delivered IUGR infants is shown in Table 3.

Table 3: Parity

\begin{tabular}{|l|c|c|c|}
\hline \multirow{2}{*}{ Parity } & \multirow{2}{*}{ Total no. of Patients } & \multicolumn{2}{|c|}{$\begin{array}{c}\text { Patients with Group II } \\
\text { Infants (IUGR) }\end{array}$} \\
\cline { 3 - 4 } & & $\mathbf{N}$ & \% \\
\hline Primigravida & 40 & 21 & 21 \\
\hline G2 & 30 & 20 & 20 \\
\hline G3 & 17 & 5 & 5 \\
\hline G4 & 10 & 8 & 8 \\
\hline G5 & 3 & 2 & 2 \\
\hline Total & 100 & 56 & 56 \\
\hline
\end{tabular}

Of the 100 patients, 63 patients (63\%) had associated high-risk factors for IUGR. The various associated factors are shown in Table 4 . Of the 63 patients, 8 patients had more than one high-risk factor. Of these 63 patients, the number of patients who ultimately delivered a group II infant was 37 (58.73\%). Of the patients with Group II infants, 6 patients (16.2\%) had previously been delivered of an infant with IUGR.

Table 4: Associated High-Risk Factors

\begin{tabular}{|l|c|c|c|}
\hline High-Risk Factor & Group I & Group II & Total \\
\hline Hypertension & 10 & 11 & 21 \\
\hline Bad obstetric history & 4 & 12 & 16 \\
\hline Post-Caesarean & 6 & 4 & 10 \\
\hline Anameia & 3 & 7 & 10 \\
\hline Heart disease & 1 & 0 & 1 \\
\hline Elderly primi & 1 & 2 & 3 \\
\hline Pulmonary TB & 1 & 0 & 1 \\
\hline Short Stature & 0 & 1 & 1 \\
\hline Total & 26 & 37 & 63 \\
\hline
\end{tabular}

Table 5: Biparietal Diameter

\begin{tabular}{|l|c|c|}
\hline Biparietal Diameter (Percentile) & $\begin{array}{c}\text { Group II } \\
\text { (SGA) }\end{array}$ & $\begin{array}{c}\text { Group I } \\
\text { (AGA) }\end{array}$ \\
\hline$<5$ th & 45 & 9 \\
\hline$>5$ th & 11 & 35 \\
\hline Total $=100$ & 56 & 44 \\
\hline
\end{tabular}

Sensitivity $=80.35 \%$; Specificity $=79.54 \%$

Predictive value of a positive test (true - positive rate) $=83.33 \%$

Predictive value of a negative test (true - negative rate) $=76.08 \%$

False positive rate $=16.66 \%$; False negative rate $=23.91 \%$ 
Table 6: Rate of growth of BPD

\begin{tabular}{|l|c|c|}
\hline $\mathbf{r}$ BPD/week & $\begin{array}{c}\text { Group II } \\
\text { (SGA) }\end{array}$ & $\begin{array}{c}\text { Group I } \\
\text { (AGA) }\end{array}$ \\
\hline$<-1$ SD & 16 & 9 \\
\hline$>-1$ SD & 12 & 41 \\
\hline Total=78 & 28 & 50 \\
\hline
\end{tabular}

Sensitivity $=57.1 \%$; Specificity $=82 \%$

Predictive value of a positive test (true - positive rate) $=64 \%$

Predictive value of a negative test (true - negative rate $=77.3 \%$

False positive rate $=36 \%$; False negative rate $=22.6 \%$

Table 7: Head Circumference

\begin{tabular}{|l|c|c|}
\hline $\begin{array}{l}\text { Head Circumference } \\
\text { (Percentile) }\end{array}$ & $\begin{array}{c}\text { Group II } \\
\text { (SGA) }\end{array}$ & $\begin{array}{c}\text { Group I } \\
\text { (AGA) }\end{array}$ \\
\hline$<5$ th & 46 & 9 \\
\hline$>5$ th & 10 & 35 \\
\hline Total $=100$ & 56 & 44 \\
\hline
\end{tabular}

Sensitivity $=82.14 \% ;$ Specificity $=79.54 \%$

Predictive value of a positive test (true-positive rate) $=83.63 \%$

Predictive value of a negative test (true-negative) $=77.77 \%$

False positive rate $=16.36 \%$; False negative rate $=22.22 \%$

Table 8: Abdominal Circumference

\begin{tabular}{|l|c|c|}
\hline $\begin{array}{l}\text { Abdominal Circumference } \\
\text { (Percentile) }\end{array}$ & $\begin{array}{c}\text { Group II } \\
\text { (SGA) }\end{array}$ & $\begin{array}{c}\text { Group I } \\
\text { (AGA) }\end{array}$ \\
\hline$<5$ th & 54 & 13 \\
\hline$>5$ th & 2 & 31 \\
\hline Total $=100$ & 56 & 44 \\
\hline
\end{tabular}

Sensitivity $=96.42 \% ;$ Specificity $=70.45 \%$

Predictive value of a positive test (true-positive rate) $=80.59 \%$

Predictive value of a negative test (true-negative) $=93.93 \%$

False positive rate $=19.40 ;$ False negative rate $=6.06 \%$

Table 9: Rate of Growth of Abdominal Circumference

\begin{tabular}{|l|c|c|}
\hline $\begin{array}{l}\mathrm{RAC} \\
(\mathrm{Cm} / 14 \text { days })\end{array}$ & $\begin{array}{c}\text { Group II } \\
\text { (SGA) }\end{array}$ & $\begin{array}{c}\text { Group I } \\
(\text { AGA })\end{array}$ \\
\hline$<10$ & 14 & 5 \\
\hline$>10$ & 8 & 31 \\
\hline Total $=100$ & 22 & 36 \\
\hline
\end{tabular}

Sensitivity $=63.3 \%$ : Specificity $=86.1 \%$

Predictive value of a positive test (true-positive rate) $=73.7 \%$

Predictive value of a negative test (true-negative rate) $=79.5 \%$

False positive rate 26.3\%; False negative rate $20.5 \%$

Table 10: Ratio of Head Circumference and Abdominal Circumference

\begin{tabular}{|l|c|c|}
\hline $\begin{array}{l}\text { HC / AC } \\
\text { (Percentile) }\end{array}$ & $\begin{array}{c}\text { Group II } \\
\text { (SGA) }\end{array}$ & $\begin{array}{c}\text { Group I } \\
\text { (AGA) }\end{array}$ \\
\hline$<95$ th & 43 & 5 \\
\hline$>95$ th & 13 & 39 \\
\hline Total $=100$ & 56 & 44 \\
\hline
\end{tabular}

Sensitivity $=93.47 \% ;$ Specificity $=88.63 \%$

Predictive value of a positive test (true-positive rate) $=89.58 \%$

Predictive value of a negative test (true-negative rate) $=75 \%$

False positive rate $=10.41 \%$; False negative rate $=25 \%$ 
Table 11: Ratio of Femoral Length and Abdominal Circumference

\begin{tabular}{|l|c|c|}
\hline FL / AC & $\begin{array}{c}\text { Group II } \\
\text { (SGA) }\end{array}$ & $\begin{array}{c}\text { Group I } \\
\text { (AGA) }\end{array}$ \\
\hline$>23.5$ & 28 & 3 \\
\hline$<23.5$ & 28 & 41 \\
\hline Total=100 & 56 & 44 \\
\hline
\end{tabular}

Sensitivity $=50 \%$; Specificity $=93.1 \%$

Predictive value of a positive test (true-positive rate) $=90.32 \%$

Predictive value of a negative test (true-negative rate) $=59.42 \%$

False positive rate $=9.67 \%$; False negative rate $=40.57 \%$

Table 12: Amniotic Fluid Volume

\begin{tabular}{|l|c|c|}
\hline Amnoitic Fluid Volume & $\begin{array}{c}\text { Group II } \\
\text { (SGA) }\end{array}$ & $\begin{array}{c}\text { Group I } \\
\text { (AGA) }\end{array}$ \\
\hline$<2 \mathrm{~cm}$ & 11 & 0 \\
\hline$>2 \mathrm{~cm}$ & 45 & 44 \\
\hline Total $=100$ & 56 & 44 \\
\hline
\end{tabular}

Sensitivity $=19.64 \% ;$ Specificity $=100 \%$

Predictive value of a positive test (true-positive rate) $=100 \%$

Predictive value of a negative test (true-negative rate) $=49.43 \%$

False positive rate $=0 \%$; False negative rate $=50.56 \%$

Table 13: Estimated Fetal Weight

\begin{tabular}{|l|c|c|}
\hline $\begin{array}{l}\text { Estimated Fetal Weight } \\
\text { (Percentile) }\end{array}$ & $\begin{array}{c}\text { Group II } \\
\text { (SGA) }\end{array}$ & $\begin{array}{c}\text { Group I } \\
\text { (AGA) }\end{array}$ \\
\hline$<10$ th & 43 & 5 \\
\hline 10 th & 13 & 39 \\
\hline Total=100 & 56 & 44 \\
\hline
\end{tabular}

Sensitivity $=76.9 \%$; Specificity $=88.63 \%$

Predictive value of a positive test (true-positive rate) $=89.5 \%$

Predictive value of a negative test (true-negative rate) $=75 \%$

False positive rate $=10.41 \%$; False negative rate $=25 \%$

Table 14: FL / AC with rAC

\begin{tabular}{|c|c|c|}
\hline $\begin{array}{l}\mathrm{rAC} \text { in } \mathrm{mm} / \mathbf{1 4} \text { days }+ \\
\mathrm{FL} / \mathrm{AC}\end{array}$ & $\begin{array}{c}\text { Group II } \\
\text { (SGA) }\end{array}$ & $\begin{array}{l}\text { Group I } \\
\text { (AGA) }\end{array}$ \\
\hline $\begin{array}{l}\mathrm{rAC}<10+ \\
\text { FL/AC }>23.5\end{array}$ & $x_{1}$ & 3 \\
\hline $\begin{array}{l}\text { rAC }>10+ \\
\text { FL/AC }<23.5\end{array}$ & 14 & 33 \\
\hline Total $=58$ & 22 & 36 \\
\hline
\end{tabular}

Sensitivity $=36.4 \% ;$ Specificity $=91.7 \%$

Predictive value of a positive test (true-positive rate) $=72.7 \%$

Predictive value of a negative test (true-negative rate) $=70.2 \%$

False positive rate $=27.3 \%$; False negative rate $=29.8 \%$

Table 15: FL/AC with AFV

\begin{tabular}{|c|c|c|}
\hline $\begin{array}{l}\text { FL/AC + } \\
\text { AFV }\end{array}$ & $\begin{array}{c}\text { Group II } \\
\text { (SGA) }\end{array}$ & $\begin{array}{c}\text { Group I } \\
\text { (AGA) }\end{array}$ \\
\hline $\begin{array}{l}\text { FL/AC }>23.5+ \\
\mathrm{AFV}<2 \mathrm{~cm}\end{array}$ & 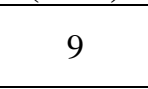 & 0 \\
\hline $\begin{array}{l}\text { FL/AC }<23.5 \text { or } \\
\mathrm{AFV}>2 \mathrm{~cm}\end{array}$ & 47 & 44 \\
\hline Total $=100$ & 56 & 44 \\
\hline
\end{tabular}

Sensitivity $=16.07 \% ;$ Specificity $=100 \%$ 
Table 16: Any Five Criteria

\begin{tabular}{|l|c|c|}
\hline $\begin{array}{l}\text { Number of test creteria } \\
\text { Positive for IUGR }\end{array}$ & $\begin{array}{c}\text { Group II } \\
\text { (SGA) }\end{array}$ & $\begin{array}{c}\text { Group I } \\
\text { (AGA) }\end{array}$ \\
\hline$>5$ & 41 & 2 \\
\hline$<5$ & 15 & 42 \\
\hline Total $=100$ & 56 & 44 \\
\hline
\end{tabular}

Sensitivity $=73.21 \%$; Specificity $=95.45 \%$

Predictive value of a positive test (true-positive rate) $=95.34 \%$

Predictive value of a negative test (true-negative rate) $=73.68 \%$

False positive rate $=4.65 \%$; False negative rate $=26.31 \%$

COMPARATIVE PERFORMANCE OF VARIOUS PARAMETERS

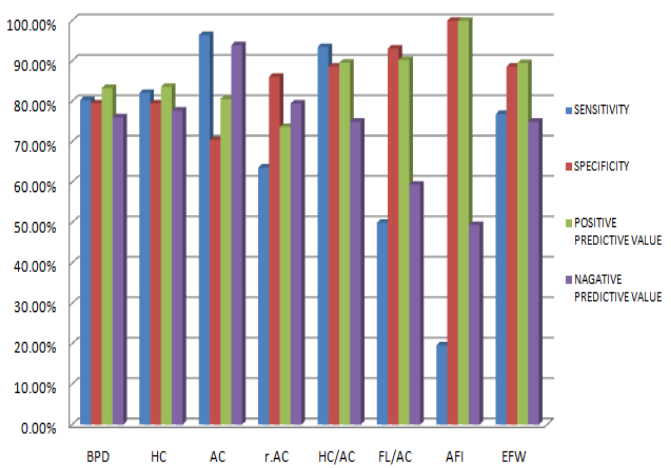

BPD \& HC Level

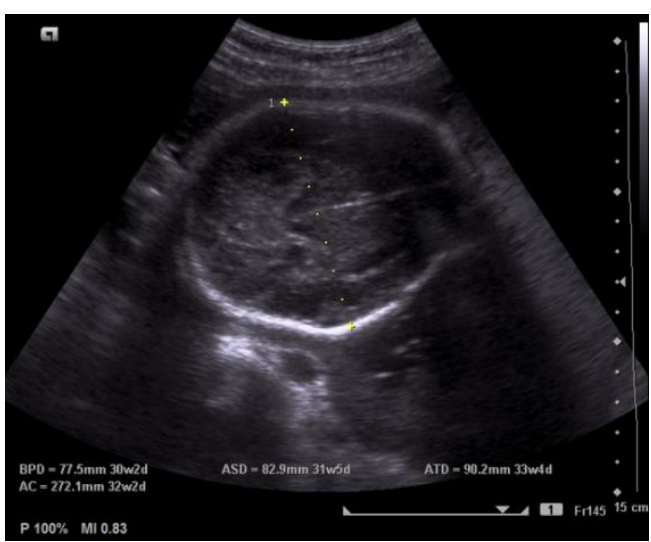

AC Level

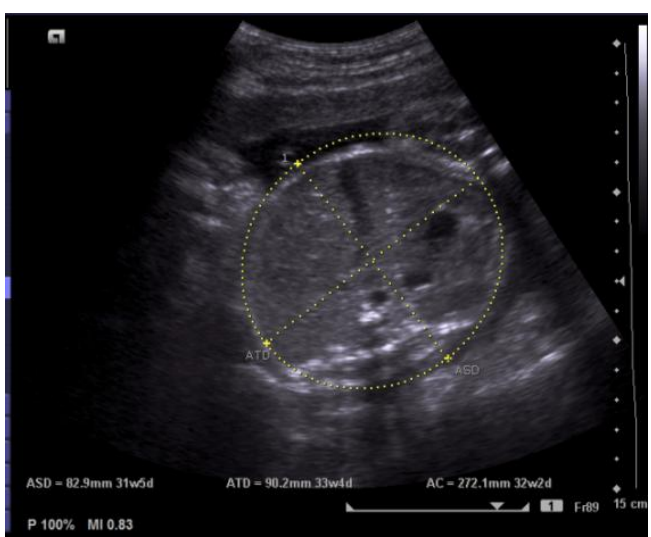

FL Level

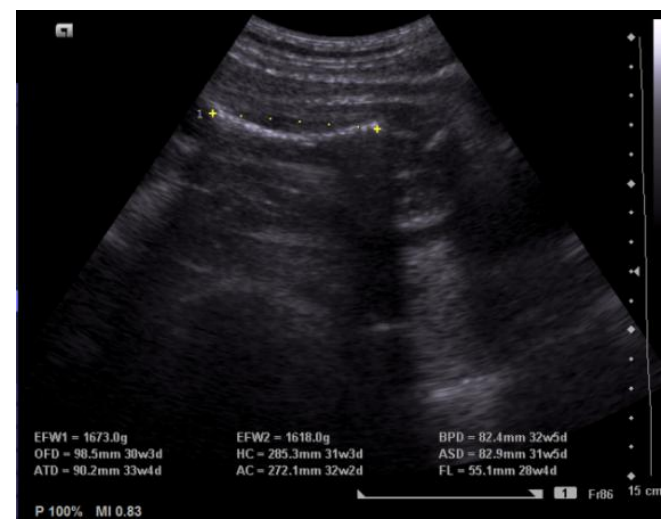

\section{Discussion}

In this study, 44 of 100 women (44\%) with the clinical suspicion of IUGR were delivered of normal infants (Table 1). Manning ${ }^{[6]}$ reported a false positive rate of $74.8 \%$ for the clinical diagnosis of IUGR. In contrast, Campbell [7] reported detection of only 35 of 115 growthretarded infants $(28.7 \%)$ by clinical methods alone. Thus, the sole use of clinical methods to detect IUGR appears to be inaccurate.

The range of age in this study population was from 18- 38 years (Table 2), the mean age being 23.2 years. No apparent increase in the incidence of IUGR was seen in any particular age group. The maximum number of patients were primigravida (40 of 100 women - 40\%). However, only $21 \%$ of primis ultimately were delivered of infants with IUGR.

There were a total of 63 associated high risk factors in the referred population of patients (Table 4). However, 8 patients had more than one high-risk factor. Hence, the total number of women with associated high-risk factors was only 55 (55\%). Hypertension was the most common high-risk factor seen ( 21 of 63 i.e., 33.3\%). There 
were 16 patients with bad obstetric history of previous stillbirths or history of delivering an infant with IUGR. Out of these, 12 patients were ultimately delivered of an infant with IUGR (12 of 16 i.e. $75 \%$ ).

The predictive value of a positive test was $82 \%$ and of a negative test was $94 \%$. Fescina et $\mathrm{al}^{[8]}$ reported a sensitivity of $67 \%$ and a specificity of $39 \%$ using single BPD measurements for the detection of IUGR. The predictive value of a positive test was $86 \%$ and have negative test $82 \%$. In the present study, a BPD measurement less than the 5th percentile for gestational age was taken as a positive indicator for growth retardation and a sensitivity of $80.35 \%$ and a specificity of $79.54 \%$ was found (Table 5). The predictive values were $83.33 \%$ for a positive test and $76.08 \%$ for a negative test. These values compare well with the above series.

\section{Rate of Growth of Biparietal Diameter (r BPD)}

In the present study, the rBPD/wk was determined and the values below - 1 SD of the reference mean were identified using the charts given by Sholl et al ${ }^{[9]}$. The sensitivity was found to be $57.1 \%$ and the specificity was $82 \%$ (Table 6). The predictive value of a positive test was found to be $64 \%$ positive and the predictive value of a negative test was $77.3 \%$ that was well comparable to a study by Sholl et $\mathrm{al}^{[9]}$.

\section{Head Circumference (HC)}

Evaluation of the BPD was associated with a sensitivity of $89 \%$ and a positive predictive value of $68 \%$. In comparison, the HC was associated with a sensitivity of $63 \%$ and a positive predictive value of $75 \%$ in a study by Warsof et al. ${ }^{[10]}$

In the present study, Table 7 showed a sensitivity of $82.14 \%$ and a specificity of $79.54 \%$. The positive predictive value of a test was $83.63 \%$ for Head circumference.

\section{Abdominal Circumference (AC)}

The results in the present study showed a sensitivity of $96.42 \%$ and specificity of $70.45 \%$ (Table 8 ). The true positive rate was $80.59 \%$, though a high true negative rate of $93.93 \%$ was found. The much higher sensitivity and lower specificity in the present study in comparison to the figures quoted in western studies is explainable on the difference between normal values for AC measurements for gestational age in Indian versus western fetuses.

\section{Rate of Growth of Abdominal Circumference (r AC)}

The rate of growth of the fetal AC was expressed in millimeters per 14 days and calculated as follows:

(Final AC - Previous AC) X 14

r AC $=$ No of days between examinations

This test was also applied in this study using the criteria of rAC $10 \mathrm{~mm} / 14$ days as the cut-offpoint to differentiate the AGA from the SGA fetus. (Table 9) The predictive values of a positive and negative test were $73.7 \%$ and $79.5 \%$ respectively. Though this test showed a similar performance to BPD and HC measurements in this study, it offers an attractive tool for differentiating between the growth retarded versus normal fetus in a case with unknown gestational age.

\section{Head \\ Circumference/Abdominal Circumference (HC/AC)}

The HC/AC ratio was calculated in the present study. Based on the normative criteria given by Campbell and Thomas ${ }^{[11]}$, the values above the 95th percentile for gestational age were identified and taken as positive indicators of IUGR. The results showed a sensitivity of $93.47 \%$ and a specificity of $88.63 \%$ (Table 10). The predictive values of both a positive test as well as a negative test were high at $89.5 \%$ and $75 \%$ respectively. The false positive and false negative rates were both low at $10.4 \%$ and $25 \%$ respectively. Thus, this test showed an overall good performance for differentiating between normal growths retarded fetuses. The results obtained in this study compare with other studies done earlier. Since it is a ratio of body proportionality, it is not affected by the 
lower absolute values of $\mathrm{HC}$ and $\mathrm{AC}$ found in the Indian population as compared to the west.

The disadvantages of this test are that this too requires an accurate knowledge of gestational age, since the HC/AC ratio differs at various gestational ages.

\section{Femoral Length / Abdominal Circumference Ratio (FL/AC)}

Hadlock et al ${ }^{[12]}$ proposed the use of the FL/AC ratio as an age-independent indicator of IGUR. The FL/AC ratio was found to have a normal range of $22 \pm 2$ throughout the second half of gestation. They evaluated this ratio as a predictor of IGUR in 30 cases using an FL/AC ratio of $23.5 \%$ as the upper limit of normal. They reported a sensitivity of $60 \%$ and a specificity of $90 \%$ for diagnosing IGUR. The true positive rate was $25 \%$ and true negative rate was $98 \%$.

In the present study, a FL/AC ratio of $\geq 23.5$ were taken as a positive indicator of IUGR. The results showed a sensitivity of $50 \%$, a specificity of $93.18 \%$, a true positive rate of $90.32 \%$ and a true negative rate of $59.42 \%$ (Table 11). These values compare well with those reported by Hadlock et al [12].

\section{Assessment of Amnoitic Fluid Volume (AFV)}

In the present study, the absence of pocket $>2 \mathrm{~cm}$ was taken as the definition of Oligohydramnios. The results (Table 12) showed Oligohydramnios in only 11 of 56 IUGR fetuses for a sensitivity of 19.64\%. However, all the cases with Oligohydramnios were ultimately delivered of neonates with IUGR, giving a specificity of $100 \%$. The true positive rate was $100 \%$ and the negative rate was $49.43 \%$. However, there was a high false negative rate of $50.56 \%$. These results compare favorably with those of Divon et al ${ }^{[13]}$.

\section{Estimated Fetal Weight (EFW)}

In the present study, fetal weight was calculated by using Hadlock's equation with $\mathrm{AC}$ and FL measurements ${ }^{[14]}$. EFW below the 10th percentile for gestational was taken as a positive indicator for IUGR. The results as shown in Table 13 show a sensitivity of $76.78 \%$ and a specificity of $88.6 \%$, and the predictive value of a positive test was $89.5 \%$ and of a negative test was $75 \%$, which are similar to the values reported by Hadlock ${ }^{[14]}$.

\section{Combination of Parameters}

Since single parameters do not seem to be accurate by themselves in diagnosing IUGR, combinations of two parameters were also evaluated in the present study. In the first combination, the test was termed positive for IUGR, if both the rAC was $\leq 10 \mathrm{~mm} / 14$ days and the FL/AC ratio was $\geq 23.5$. The results (Table 14) showed a very low sensitivity of $36.4 \%$ but a high specificity of $91.7 \%$. The same combination of parameters was evaluated by Divon et al ${ }^{[13]}$. They found a sensitivity of $40 \%$ and a specificity of $74 \%$. The results of the present study compare favorable with these values. In the second combination, the test was deemed positive if both the FL/AC ratio was $\geq 23.5$ and the qualitative $\mathrm{AFV}$ was $\leq 2.0 \mathrm{~cm}$. This resulted in a sensitivity of $16.07 \%$ and a specificity of $100 \%$ (Table 15). Divon et al ${ }^{[13]}$ reported a sensitivity of $10 \%$ and a specificity of $100 \%$ using the same combination of criteria. Again, the results of the present study have shown similar values. The last combination of criteria, which was tested, was that a minimum number of any five criteria should be positive for the test to be deemed positive for IUGR. The results as shown in table 16 reveal a moderate sensitivity of $73.21 \%$, a very high specificity of $95.45 \%$ and high predictive values of $95.34 \%$ for positive test and $73.68 \%$ for a negative test. The false positive and negative rates were also very low at $4.6 \%$ and $26.3 \%$ respectively.

Thus, combining criteria for detecting IUGR results in very high specificity but does not increase the sensitivity to a similar extent.

\section{Comparitive Performance of Parameters}

As far single parameters are concerned, the overall best performance as seen in this study was by EFW and the HC/AC ratio, both of which gave 
identical results. They showed a moderately high sensitivity of $76.7 \%$ and $93.47 \%$, a high specificity of $88.6 \%$ and high positive predictive values of $89.5 \%$ and $89.5 \%$ respectively. The false positive and negative values were also reasonably low at $10.4 \%$ and $25 \%$ b respectively.

For screening the general population, a highly sensitive indicator is required. The highest sensitivity of $96.42 \%$ was by using AC measurements as the parameter. As discussed earlier, this probably due to the lower AC measurements in Indian fetuses as compared to western standards. EFW, HC/AC ratio, BPD and $\mathrm{HC}$ measurements had similar sensitivities in the range of $76.7 \%-93.47 \%$. The lowest sensitivity was shown by the qualitative determination of AFV (19.64\%), which precludes its use as a screening test for the population.

As compared to the sensitivity, most of the parameters evaluated in this study showed higher specificity values except for the $\mathrm{AC}$, which gave a lower specificity. HC and BPD measurements gave similar sensitivity and specificity values. Qualitative AFV determination showed the highest specificity of $100 \%$ followed by FL/AC (93.18\%), and EFW and $\mathrm{HC} / \mathrm{AC}$ ratio (88.63\%). The rAC also showed a high specificity of $86.1 \%$. The predictive values of a positive test of or the true positive rates was the highest for qualitative AFV determination (100\%), followed by EFW and $\mathrm{HC} / \mathrm{AC}$ ratio with $89.58 \%$. On the other hand, the predictive value for a negative test was the highest for AC measurement (93.9\%). The EFW, $\mathrm{HC} / \mathrm{AC}$ ratio, $\mathrm{HC}$ and BPD measurements showed similar values in the range of $75-77 \%$.

These results indicate that although proposed sonographic parameters may identify a group of fetuses that warrant close antepartum surveillance, none of these parameters allows one to make a confident diagnosis of IUGR in a fetus. In fact, most of the parameters allow one to exclude IUGR with reliability rather than confirm IUGR. The best hope for reliable sonographic diagnosis of IUGR lies in the use of multiple parameters, which give better positive and negative predictive values.

\section{Summary and Conclusion}

Hence it is observed from this study that the use of sonographic measurements for the diagnosis of IUGR is associated with a high specificity and a somewhat lower sensitivity. The highest sensitivity of $96.42 \%$ obtained was by using AC measurement followed by $93.47 \%$ by using $\mathrm{HC} / \mathrm{AC}$ ratio. The highest specificity of $100 \%$ is obtained by using AFV determination, followed by FL/AC $93.8 \%$. Therefore, the current ultrasound methods seem to be more useful for excluding the possibility of abnormal fetal growth rather than confirming it. However, in this study, combination of multiple parameters has resulted in a high positive predictive rate of $95.35 \%$ for the diagnosis of intrauterine growth retardation.

\section{References}

1. Lubchenco LO, Hansman C, Dressler M. et al. Intra uterine growth as estimated from live born, birth weight data at 24-2 weeks of gestation. Pediatrics 1963:32: 793-795.

2. Family welfare programme in India year book, 1992-93. Ministry of Health and Family Welfare, Government of India, New Delhi.

3. Morrison I, Olson J. Weight specific stillbirths and associated cause of death: An analysis of 765 consecutive still births. Am J Obstet Gynaecol 1985; 152: 975980.

4. World Heath Statistics Quarterly WHO 1995; 48: 264.

5. Ballard JL, Novak K, Driver M. A simplified score for assessment of fetal maturation of new born infants, J Pediatr 1979; 95: 769-772.

6. Manning FA, Hill LM, Platt LD. Qualitative amniotic fluid volume determination by ultrasound: Antepartum detection of intra uterine growth 
retardation. AM J Obstet Gynecol 1981; 139: 254-258.

7. Campbell S, Dewhurst CJ. Diagnosis of the small-for-dates fetus by serial ultrasonic cephalometry. Lancet 1971; 2: 1002-1006.

8. Fescina RH, Martell M, Martiez G,Latra L, Schwarcz R. Small for dates; Evaluation of different diagnostic methods. Acta Obstet Gyanecol Scan 1987; 66: 221-226.

9. Sholl JS, Woo D, Rubin JM et al. Intra uterine growth retardation risk detection for fetuses of unknown gestational age. Am J Obstet Gynaecol 1982; 144: 709714.

10. Warsoff SL, Cooper GJ, Little D, Campbell S. Routine ultra sound screening for antenatal detection of intra uterine growth retardation. Obstet Gynecol 1986;67: 33-37.

11. Campbell S, Thomas A. Ultrasound measurement of the fetal head to abdominal circumference ratio in the assessment of growth retardation. Br. J Obstet Gynecol 1977;84: 165-174.

12. Hadlock FP, Deter RL, Harrist RB, Roecker E, Park SK. A date independent predictor of intra uterine growth retardation: Femur length/Abdominal Circumference ratio. AJR 1983; 141: 979984.

13. Divon MY, Platt LD, Sipos L, et al. Identification of the small-for-gestational age fetus with the use of gestational age independent indices of fetal growth. Am J Obstet gynecol 1986; 155: 1197-1201.

14. Hadlock FP, Harrist RB, Sharman RS, Deter RL, Park SK. Estimation of fetal weight with the use of head, body and femur measurements - A prospective study. Am J Obstet Gynecol 1985; 151: 333-337. 